\title{
ADAPTAÇÃO DE MATERIAL DIDÁTICO PARA O PROJETO UCA
}

\author{
Heli Meurer - PPGIE/ UFRGS - heli.meurer@gmail.com \\ Patrícia da Silva Campelo Costa - PPGIE/ UFRGS - patricia.campelo@ yahoo.com \\ Jaqueline Maissiat - PPGIE/ UFRGS - jmaissiat@yahoo.com.br \\ Claudia Zanatta - Instituto de Artes/UFRGS - claudia.zanatta@ufrgs.br \\ Juliano Varella de Carvalho - Universidade Feevale - julianovc@feevale.br \\ Eliseo Berni Reategui - PPGIE/UFRGS - eliseoreategui@gmail.com
}

Resumo: Este trabalho tem por objetivo apresentar um processo de adaptação de aulas para o contexto do Projeto UCA (Um computador por Aluno). Partindo de aulas postadas no Portal do Professor, algumas das tarefas lá disponibilizadas precisam sofrer remodelação de modo a se adequar ao contexto do UCA. Para tanto, foram adotados procedimentos que enfatizam o laptop como um veículo promotor de mediação tecnológica, a partir do qual o professor pode aplicar tarefas em aula. $O$ processo de adaptação das aulas exigiu um trabalho interdisciplinar, de modo que a postagem das aulas estivesse de acordo com as orientações do UCA. A partir disso, observou-se que os professores podem fazer uso de material didático adaptado à sua práxis pedagógica, de modo a levar em consideração o conteúdo didático e a mediação do computador.

Palavras-chave: projeto UCA, material didático, mediação tecnológica

\section{ADAPTATION OF EDUCATIONAL MATERIAL FOR THE OLPC PROJECT IN BRAZIL}

\begin{abstract}
This paper presents a process of adaption of classes to the context of the UCA Project (equivalent to the project One laptop per child in Brazil). Having as a starting point some lessons posted in Portal do Professor (an institutional website for teachers), some of the tasks present in this page have to go through several adjustments in order to suit the UCA Project's context. This way, we have adopted procedures that consider the laptop a means of promoting technological mediation, through which the teacher can apply tasks in class. The process of adapting lessons required an interdisciplinary work, so that the classes were posted according to the UCA guidelines. We have therefore observed that teachers can make use of teaching materials adapted to their pedagogical practice, in order to take into account educational content and the computer mediation.
\end{abstract}

Keywords: OLPC Project, didactic material, technological mediation 


\section{Introdução}

Quando, em 2005, Nicholas Negroponte do MIT (Instituto de Tecnologia de Massachusetts) idealizou o laptop XO (The Children's Machine), uma de suas principais preocupações era a de desenvolver um projeto de inclusão digital diretamente voltado à educação com o objetivo de difundir o conhecimento e novas tecnologias a todas as crianças do mundo. Para que isso fosse possível, o laptop teria que possuir um preço acessível e de preferência ser financiado por órgãos internacionais ou por governos interessados no projeto. Além disso, características como o fácil acesso a um vasto contexto informacional na web, a interatividade ativa e a multimídia decorrente da convergência midiática oferecem um conjunto de possibilidades que podem contribuir muito para o desenvolvimento intelecto-cognitivo, afetivo e psicomotor das crianças do ensino fundamental.

A grande repercussão do projeto de Negroponte, difundido pela ONG internacional OLPC (One Laptop Per Child) sensibilizou o governo brasileiro, principalmente pela acessibilidade e o caráter democrático do mesmo e contribuiu para implantação do Projeto UCA (Um Computador por Aluno). Ainda em fase experimental, 150 mil pequenos laptops foram distribuídos para diferentes estados do país para serem analisados e experimentados em projetos pilotos em escolas e para que, através dos mesmos, fosse possível definir modelos pedagógicos adequados às possibilidades e às ferramentas que o computador oferece. O laptop do projeto UCA, além de oferecer uma série de ferramentas instaladas em seu sistema operacional, acessa a world wide web (www) e abre um leque de possibilidades para o desenvolvimento de novos aplicativos e ferramentas capazes de qualificar a experiência educacional.

Observa-se que no contexto brasileiro os custos de equipamentos e de acesso à internet ainda são elevados e, muitas vezes, inacessíveis à grande parte da população. Nesse cenário, a relação 1:1 (um computador para cada aluno) é um projeto políticopedagógico que implica em um esforço para viabilizar o acesso às TICs, instrumentalizando e capacitando alunos e professores no que se refere ao uso de um sistema digital de informação, inserindo-os em um processo educacional vinculado a uma concepção de compartilhamento e de geração de conhecimentos em rede.

Contudo, o êxito do projeto UCA está diretamente ligado à adesão dos professores de escolas públicas no país todo, de modo que o laptop seja usado em suas práticas. Assim, vemos que em projetos que visam transformar o "paradigma da educação convencional' com a introdução da tecnologia da informação, é importante considerar que a tecnologia começa a fazer parte do cotidiano de professores e alunos e exige, no mínimo, a reorganização e reestruturação dos processos educacionais (Kenski, 2007). Visto que treinamentos e orientações são fundamentais neste processo, o objetivo deste trabalho é apresentar uma proposta de adaptação de material didático postado no Portal do Professor ${ }^{1}$, a partir da qual tarefas são remodeladas para o contexto do projeto UCA.

\section{Do contexto nacional ao grupo de trabalho no Rio Grande do Sul}

Em 2005, durante o Fórum Econômico Mundial em Davos, na Suíça, o projeto UCA foi apresentado ao governo brasileiro. A proposta, então, foi adotada pelo governo federal, que decidiu implantar TICs nas escolas, por meio da distribuição de computadores portáteis aos alunos da rede pública de ensino. A partir disso, foi decidido que o UCA teria projetos pilotos realizados em cinco escolas de quatro estados 
brasileiros (Rio de Janeiro, Rio Grande do Sul, São Paulo e Tocantins), além do Distrito Federal. De acordo com Kist (2008), a partir dos objetivos propostos pelo OLPC, o UCA definiu os seguintes propósitos em contexto educacional brasileiro: a) promover a inclusão digital, por meio da distribuição, em escolas públicas, de um computador para cada estudante e professor de educação básica; b) alterar a educação centrada no professor para uma pedagogia centrada no desenvolvimento autônomo, baseado na cooperação entre alunos; c) permitir que os alunos passem a ser protagonistas do processo de construção do conhecimento.

O ano de 2006 foi a época de difusão do Projeto no Brasil, visto que o Ministério da Educação recebeu as primeiras unidades do computador portátil que seria usado no UCA. Assim, tais máquinas puderam passar por um período de avaliações técnicas e funcionais. Um ano mais tarde, cinco escolas foram escolhidas para sedear projetos pilotos, a fim de que os principais impactos, bem como os problemas de implantação, pudessem ser examinados. Nas cidades de São Paulo, Porto Alegre, Palmas, Piraí e Brasília tais pilotos iniciariam.

Conforme Kist et al (2007), no Instituto de Psicologia da UFRGS ocorreu o lançamento oficial do Projeto piloto UCA no Rio Grande do Sul. A Escola Estadual de Ensino Fundamental Luciana de Abreu seria apoiada pela universidade na realização da primeira experiência-piloto do país. Mais tarde, no mesmo ano de 2007, foram iniciados os experimentos em uma escola de São Paulo. Sob a coordenação de Roseli de Deus Lopes, na USP, e Léa Fagundes, no Laboratório de Estudos Cognitivos (LEC) da UFRGS, as equipes de trabalho iniciaram suas cooperações com as escolas nas quais os pilotos eram conduzidos.

Ainda em 2007, foram estruturados GTs ${ }^{2}$ para formação, acompanhamento, avaliação e pesquisa com o objetivo de fornecer subsídios para a elaboração das Diretrizes e Princípios do Projeto UCA e do Projeto de Formação Brasil. Em 2009, teve início uma segunda etapa dedicada à seleção de escolas piloto para a implementação do projeto e para capacitação dos professores para iniciar as atividades com os alunos em sala de aula.

No Rio Grande do Sul, em 2010, foi organizada uma equipe de trabalho com profissionais de diferentes áreas (Informática na Educação, Artes, Design, dentre outras) para a geração de aulas de acordo com as Diretrizes e Princípios do UCA. Desse modo, buscou-se disponibilizar, no Portal do Professor, uma adaptação de material didático a ser usado no Projeto UCA.

O objetivo principal do GT do Rio Grande do Sul é oferecer sugestões (não modelos) para atividades educativas com o uso do laptop no Ensino Fundamental. Tais referenciais são propostos mediante a adaptação, produção de conteúdos e geração de estratégias pedagógicas que possam qualificar a integração do laptop ao currículo. Oferecer referenciais para a abordagem dos conteúdos, mediados pela tecnologia do computador portátil, significa uma possibilidade de adoção dessas estratégias nos contextos mais diversos de salas de aula das escolas brasileiras. Assim, há a possibilidade de haver tanto um processo de inclusão digital quanto de inclusão social, a partir do qual a tecnologia atua como mediadora de ocasiões que possam fomentar a aprendizagem. Segundo Passerino e Montardo (2007, p.5), a inclusão social "é um processo social que visa fundamentalmente a oferecer oportunidades aos diferentes indivíduos de se autoposicionar". Além disso, para as autoras, a inclusão digital requer um entrelaçamento entre os sistemas relativos às tecnologias de informação e comunicação (TICs) e os processos sociais das comunidades.

A elaboração das aulas segue os Parâmetros Curriculares Nacionais (1997, 1998) e leva em conta três princípios orientadores básicos na produção de conteúdos: a) 
autonomia: não somente na instrumentalização para o uso do laptop e capacitação para busca de informação em rede, mas também quanto à utilização e produção de conhecimento; b) cooperação: concepção de trabalho em rede; c) mobilidade: uso do laptop tanto no ambiente escolar quanto em outros espaços.

\section{A Elaboração de material didático}

As aulas desenvolvidas para o laptop, com indicação do Ministério da Educação, são desenvolvidas a partir de aulas já enviadas, avaliadas e publicadas no Portal do Professor por professores de distintas áreas e de todo o território nacional. Desse modo, os professores, a partir de um planejamento de aula tendo por base o conteúdo, podem agregar as novas tecnologias de comunicação e informação para uma mediação tecnológica, aqui enfatizando o uso do laptop e seus recursos.

Ao analisar uma aula para desenvolvimento de outra a partir desse primeiro modelo, além de se atender o conteúdo base, são também levados em consideração os recursos do laptop - a partir do uso de softwares e materiais que sejam compatíveis. Ademais, busca-se rever os objetivos que se pretende alcançar, o tempo de desenvolvimento da aula e o processo avaliativo. Assim, esse processo de adaptação de atividades vai ao encontro da ideia de design instrucional de Filatro (2007). Partindo da idéia de um ciclo que envolva análise, projeto, desenvolvimento, implementação e avaliação, a composição do design instrucional é de caráter dinâmico e permite a contextualização de tarefas didáticas à medida que é implantado.

Também é importante salientar a importância de se pensar no planejamento de aulas, visto que o provimento de computadores para professores e alunos é apenas a primeira parte de um plano educacional pleno. Conforme Warschauer (2006), é essencial que um projeto não atente somente para o hardware e o software, mas que os sistemas social e humano também estejam em foco. Desse modo, devemos considerar um modelo de acesso que não se baseie apenas na presença de equipamentos e conectividade, pois essa seria apenas uma primeira fase para o amplo acesso digital. Assim, conforme o autor, temos as seguintes variáveis de recursos essenciais para a boa execução de um projeto digital e social: a) Recursos Físicos - compostos, por exemplo, por computadores e conectividade; b) Recursos Digitais - material online relativo a conteúdo e linguagem; c) Recursos Humanos - relativo ao letramento e à educação. Assim, nossa etapa de adaptação de material didático para o projeto UCA se encaixa na elaboração de recursos digitais, de maneira a promover um melhor aproveitamento das tecnologias por parte do professor, em suas práticas escolares.

\section{Elaborando aulas no contexto do projeto UCA}

Schneiderman (2006, p. 135) define o que considera importante num prospecto futuro de ensino e aprendizagem: "(1) estimular o contato do estudante com suas habilidades; (2) estimular a cooperação entre os alunos; (3) estimular o aprendizado ativo; (4) produzir um retorno rápido; (5) enfatizar o tempo aplicado na tarefa; (6) comunicar altas expectativas e (7) respeitar talentos e formas de aprendizado diversos". Desse modo, a adaptação de aulas para o projeto UCA se baseia em tarefas que promovam as características indicadas pelo autor.

A fim de guiar a elaboração dessas aulas para o projeto UCA, optou-se pela utilização da noção de design instrucional de Filatro (2007) e da metodologia de Meurer e Szabluk (2009) chamada de Projeto E. O design instrucional inclui estratégias para "esquematizar os elementos fundamentais de uma situação didática" (Filatro, 2007, 
p.66). Para tanto, leva em consideração as seguintes fases: a) análise; b) design; c) desenvolvimento; d) implementação; e) avaliação. Por sua vez, a abordagem metodológica do Projeto $E$ tem sua estrutura baseada na metodologia proposta por Garrett (2003), com foco na experiência do usuário. Além disso, o Projeto E traz em sua base operacional, e em sua estrutura, processos, métodos e conceitos oriundos do design e da tecnologia da informação. Para o presente trabalho, adaptamos o Projeto E, de modo a relacioná-lo com o processo de preparação e planejamento de sequências didáticas. A metodologia se divide em seis etapas, todas começando com a letra 'e'. São elas: a) estratégia; b) escopo; c) estrutura; d) esqueleto; e) estética; f) execução. Abaixo, na figura 1 é possível observar um esquema gráfico de como a metodologia do Projeto $E$ está estruturada e em que momentos ocorrem as diferentes etapas do projeto.

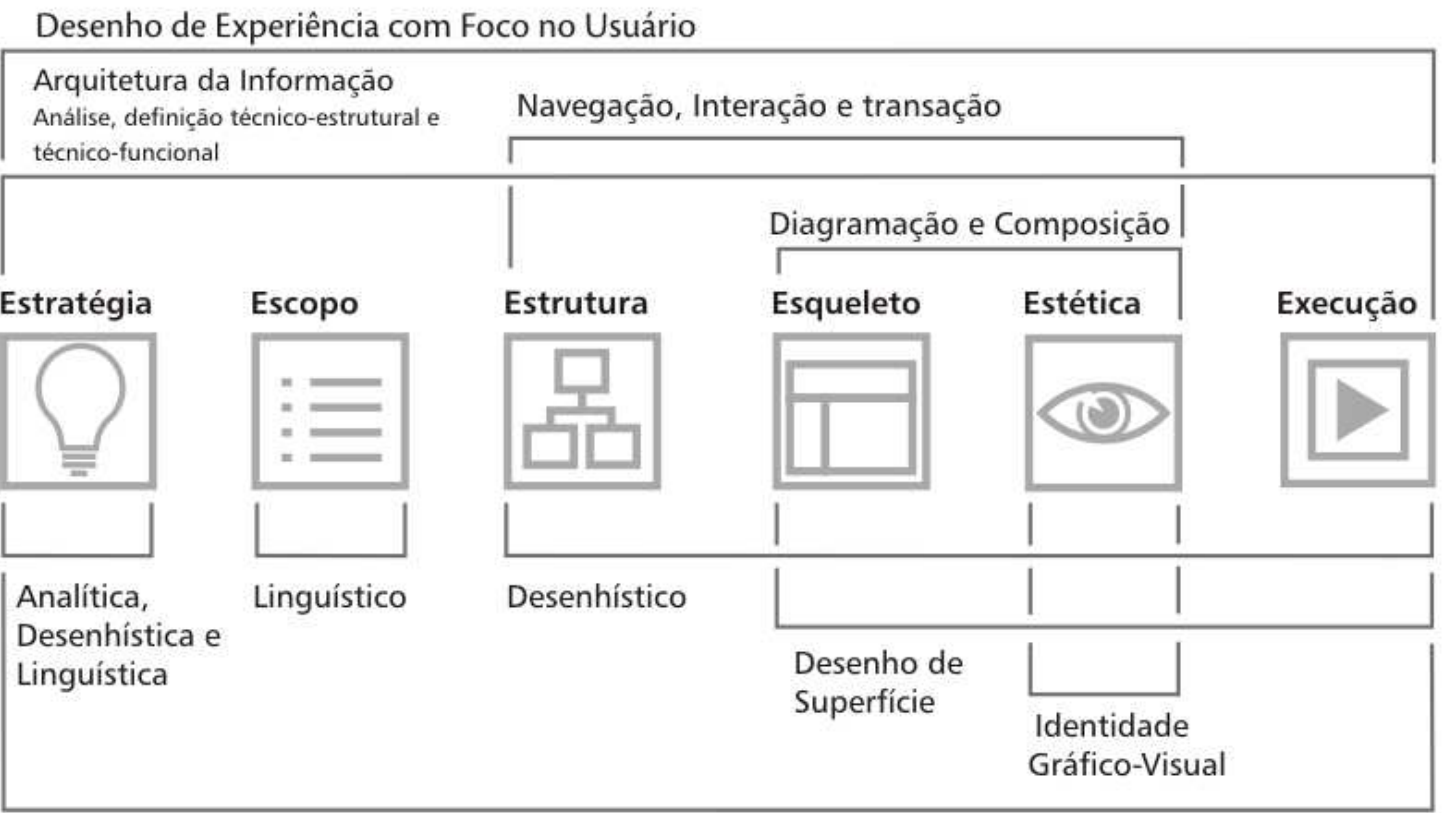

Ergonomia Cognitiva (usabilidade e acessibilidade)

Figura 1 - Estrutura do Projeto E (Meurer e Szabluk, 2009)

Na figura 1, pode-se observar uma representação simplificada dos seis passos que são seguidos na elaboração da aula adaptada com foco na utilização dos laptops educacionais. Usou-se o projeto E como referência para definir esse procedimento, pois o mesmo oferece uma série de subsídios passíveis de ajudar na elaboração de aulas que explorem melhor tanto o conteúdo temático quanto as possibilidades de uso da tecnologia.

A seguir, é apresentado um detalhamento de como os seis passos se enquadram nas etapas do Projeto E:

1. Estratégia. É dividida em três partes. Inicia-se sempre pela problematização e contextualização do que se pretende desenvolver. Em seguida, seguem as análises de exemplos similares contextualizados no meio digital. A estratégia é concluída com uma lista de verificação que procura definir quais são as possíveis restrições, requisitos e possibilidades de cada aula planejada.

2. Escopo. É relativo à definição e hierarquização do conteúdo, definição e escolha das ferramentas. Essa etapa equivale ao que Filatro (2007) chama de estágio de 
Análise, no design instrucional, na qual há uma caracterização do público-alvo e estabelecimento de objetivos para a aula específica.

3. Estrutura. Nesse momento, há uma definição do organograma da aula e das tarefas. É na estrutura que são estabelecidas todas as inter-relações entre as atividades. Apesar de haver um estabelecimento dessas atividades, o professor participante do projeto UCA tem a liberdade de adaptá-la conforme seu contexto específico. Conforme Schunk, Pintrich e Meece (2008), os professores devem estar preocupadas em não apenas atingir objetivos pedagógicos, mas também com atividades que despertem o interesse por parte dos alunos. Assim, segundo os autores, pode existir uma influência recíproca entre professores e alunos. Os professores teriam, então, a oportunidade de afetar a motivação e as oportunidades de aprendizado do aluno através do planejamento e da instrução, mas as reações dos aprendizes à instrução podem provocar a implementação de novas estratégias pelo docente. Nessa etapa de Estrutura há um detalhamento de tarefas, a partir da criação de orientações para cada atividade. Conforme Rosenshine e Stevens (1986) esse momento de explanação, no qual são incluídas instruções claras e detalhadas sobre cada atividade, é essencial para um ensino que tente ser eficaz. Além disso, quando há a inclusão de um dispositivo tecnológico, parece ser ainda mais importante a inclusão de direcionamentos claros em relação às ações pedagógicas.

4. Esqueleto. É estabelecida a densidade informacional de cada etapa da aula. Nesse estágio, são organizados os elementos da aula na tela do Portal do Professor, onde o material é postado. São organizadas as seções a seguir: a) Título e estrutura curricular; b) Dados da aula; c) Estratégias e Recursos; d)Avaliação. No design instrucional de Filatro (2007), a etapa de Design incluiria a fase Esqueleto e a anterior de Estrutura. O Design compreende "a definição da grade curricular; a seleção de estratégias pedagógicas e tecnológicas" (p.67). Para as aulas do UCA, cada componente do grupo de adaptação fica responsável por uma aula diferente, a qual se relaciona a alguma das seguintes áreas do Ensino Fundamental: Português, Ciências, Matemática, História, Geografia, Artes, Música, Educação Física ou Língua Estrangeira. Logo após a construção das tarefas, essas aulas são redistribuídas entre os próprios membros da equipe para que sejam vistas e avaliadas por mais de uma pessoa antes da postagem no Portal do Professor.

5. Estética. Define a estética-formal da aula. Ocorre logo após a definição do esqueleto do projeto. Nessa etapa, há um trabalho forte da equipe multidisciplinar, pois questões relacionadas ao design estético são levadas em consideração. São definidos, então, padrões cromáticos, fontes tipográficas, fundos imagéticos, estilos gráficos, etc. Essa etapa se refere ao que Filatro (2007, p.67) chama de Desenvolvimento, no qual há "a montagem e configuração de ambientes".

6. Execução. Depois da elaboração da aula adaptada ao contexto do UCA há uma postagem, no Portal do Professor, desse novo material remodelado. Segundo Filatro (2007), essa seria a etapa de Implementação "quando ocorre a aplicação da proposta de design instrucional".

Além da metodologia do Projeto E e do design instrucional, outros autores também se preocupam com a estruturação do material didático relacionado à incorporação das tecnologias. Para Behar (2009), é essencial a construção de uma arquitetura pedagógica que esteja focada no planejamento pedagógico, no conteúdo, na 
criação de atividades e na escolha de um ambiente de aprendizagem. Conforme a autora, os aspectos organizações de planejamento envolvem os objetivos "do ensinoaprendizagem a distância, a organização do tempo e do espaço e as expectativas na relação da atuação dos participantes ou da também chamada organização social da classe" (Behar, 2009, p.25).

Após o processo explicitado nas etapas acima, as aulas ficam disponibilizadas no Portal e podem ser consultadas livremente. As figuras 2, 3 e 4 mostram trechos de uma aula sobre a dengue postada no Portal do Professor. No exemplo, foram seguidas as etapas anteriormente citadas para se alcançar o resultado apresentado.

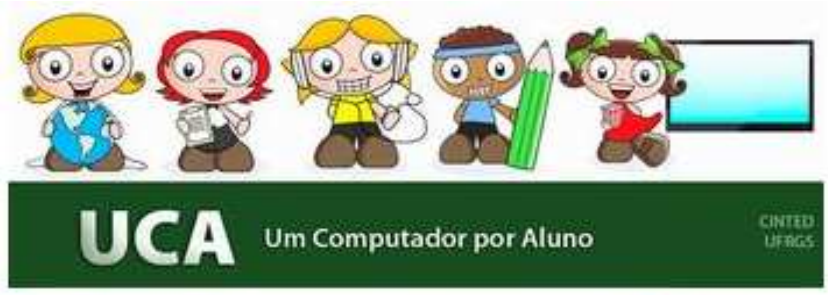

A aula envolverá os seguintes recursos do laptop:

$\begin{array}{lc}\text { Kword } & \text { [Iniciar }>\text { Aplicativos } \rightarrow \text { Kword] } \\ \text { Mozilla Firefox } & \text { [Iniciar } \rightarrow \text { Aplicativos }>\text { Internet] } \\ \text { Wx Cam } & \text { [Iniciar }>\text { Aplicativos }>\text { Multimidia] } \\ \text { Kpresenter } & \text { [Iniciar }>\text { Aplicativos }>\text { Kpresenter] }\end{array}$

Figura 2 - Recursos computacionais a serem utilizados na aula

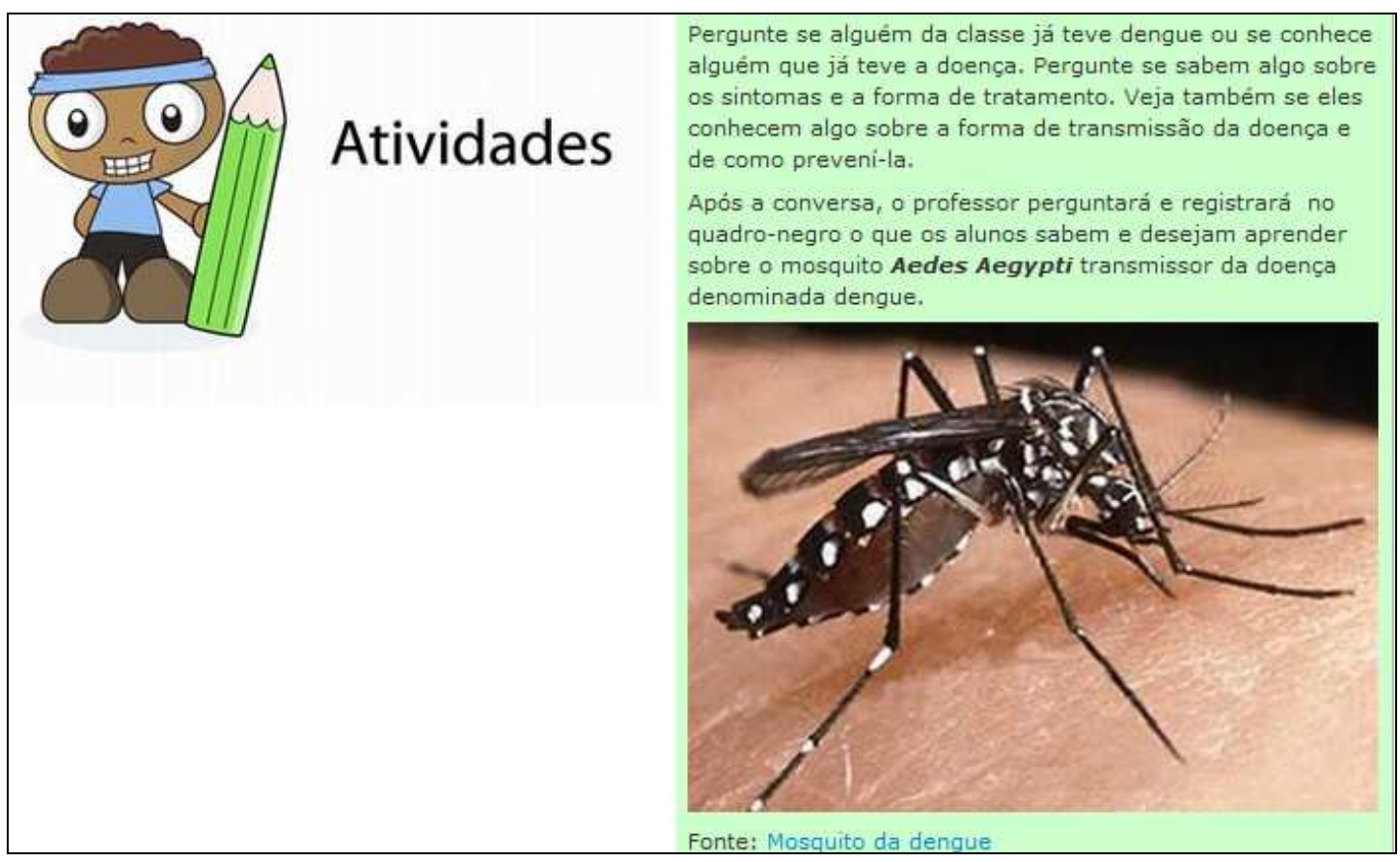

Figura 3 - Atividade baseada em discussão sobre a dengue 


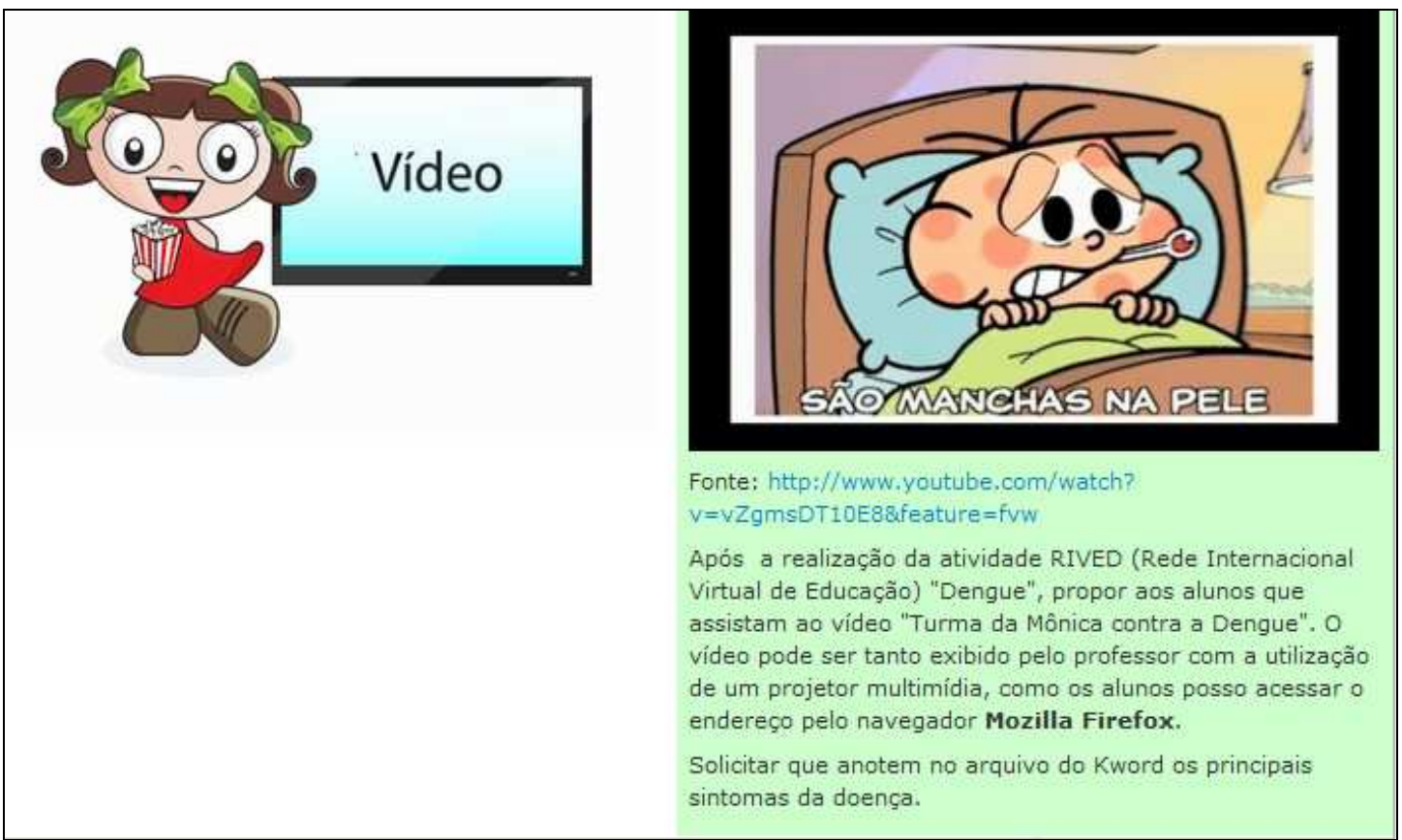

Figura 4 - Proposta de utilização de vídeo

É importante enfatizar que nem todas as atividades propostas nas aulas exigem a utilização do laptop. No exemplo ilustrado na figura 3, propõe-se que o professor realize uma discussão com os alunos registrando alguns fatos no quadro-negro, num contexto de sala de aula que lhe é mais familiar. Esta combinação dos recursos tecnológicos com atividades com as quais o educador está mais habituado, é importante para lhe mostrar como o laptop pode complementar suas práticas pedagógicas correntes.

Conforme o design instrucional, haveria mais uma etapa de Avaliação, que "inclui a consideração sobre a eficácia do curso e a eficiência do sistema" (Filatro, 2007, p.67). Tal fase de Avaliação consiste no prospecto futuro de nosso trabalho, a partir do qual professores poderão avaliar a incorporação dos materiais adaptados em suas aulas.

\section{Considerações Finais}

As reflexões e propostas deste trabalho almejam contribuir para o processo de produção de material didático para o meio digital, em especial aquele relativo ao contexto do Projeto UCA. De maneira mais ampla, a discussão em torno da elaboração desse material pode ser estendida a qualquer espaço em que o meio digital se torna um mediador no processo de aprendizagem. Conforme Warschauer (2006, p. 21), "a exclusão digital caracteriza-se não apenas pelo acesso físico a computadores e à conectividade, mas também a recursos adicionais, que permitem que as pessoas utilizem a tecnologia de modo satisfatório". Assim, os professores têm de lidar com o desafio constante de criarem atividades significativas, a partir do uso do equipamento 
eletrônico, de modo a não encarar o computador de uma perspectiva de inclusão tecnológica apenas. Ainda segundo Warschauer (2006), para o desenvolvimento de um projeto embasado em termos digitais, pedagógicos e sociais, os sistemas sociais têm de trabalhar de modo organizado e concatenado de modo a não ficarem sujeitos a uma tecnologia de vitrine. Por isso, vemos a importância de fornecer mais que apenas os recursos físicos e enfatizar os sistemas social e humano, de maneira a objetivar uma inclusão completa. Assim, acreditamos que tal processo de pensar na inclusão já inicia na etapa de elaboração de material didático.

Como planejamento futuro, será feita uma pesquisa com grupos de professores que atuam no Ensino Fundamental da rede pública, no Projeto UCA, a fim de se averiguar como as aulas adaptadas podem ser de fato incorporadas na sua práxis escolar. Destarte, espera-se observar os processos de adequação e flexibilização que os professores conduzem a partir do material didático adaptado ao Projeto UCA.

\footnotetext{
${ }^{1}$ O Portal do Professor é uma página que foi lançada em 2008, em uma parceria do Ministério da Educação com o Ministério da Ciência e Tecnologia (http://portaldoprofessor.mec.gov.br).

${ }^{2}$ Essa primeira etapa contou com profissionais vinculados à área de Informática na Educação, atuantes em universidades de diferentes regiões do Brasil: Léa da Cruz Fagundes (UFRGS), Mauro Cavalcante Pequeno (UFC), Maria Elizabeth Bianconcini de Almeida (PUC/SP), Paulo Gileno Cysneiros (UFPE), Roseli de Deus Lopes (USP) e José Armando Valente. (Unicamp).
}

\section{Referências Bibliográficas}

BEHAR, P. Modelos pedagógicos em educação a distância. In: BEHAR, P. (Org.) Modelos pedagógicos em educação a distância. Porto Alegre: Artmed, 2009. p. 15-32.

BRASIL. MEC. Parâmetros Curriculares Nacionais ( $1^{\mathbf{a}}$ a $4^{\mathrm{a}}$ séries). Brasília: MEC/SEF, 1997.

BRASIL. MEC. Parâmetros Curriculares Nacionais $\left(5^{a}\right.$ a $8^{\text {a }}$ séries). Brasília: MEC/SEF,1998.

FILATRO, A. Design instrucional e contextualizado: educação e tecnologia. São Paulo: Editora SENAC São Paulo, 2007.

GARRETT, Jesse James. The Elements of User Experience. New York: AIGA American Institute of Graphic Arts, 2003.

KENSKI, V. Educação e Tecnologias: o novo ritmo da informação. Campinas: Papirus, 2007.

KIST, S. Um laptop por criança: implicações para as práticas de leitura e escrita. Dissertação (Mestrado em Educação) - Universidade Federal do Rio Grande do Sul, Porto Alegre, 2008.

KIST, S.; SHÄFER, P.; BITTENCOURT, J.; FAGUNDES, L. Impacto da modalidade 1:1 nas práticas de leitura e escrita: primeiros resultados. In: Simpósio Brasileiro de Informática na Educação, 2007, Florianópolis. Anais do SBIE, 2007, p.442- 451. 
MEURER, H.; SZABLUK, D. Projeto E: aspectos metodológicos para o desenvolvimento de projetos dígito-virtuais. In: 9 ERGODESIGN | 9 USIHC, 2009, Curitiba. Anais do 9 ERGODESIGN | 9 USIHC, 2009.

ROSENSHINE, B.; STEVENS, R. Teaching functions. In: WITTROCK, M. (Ed.) Handbook of research on teaching. New York, Macmillan, 1986, p. 376-391.

SCHUNK, D.; PINTRICH, P.; MEECE, J. Motivation in Education: Theory, research, and applications. Chapter 9 - Teacher Influences. New Jersey: Pearson, 2008.

SHNEIDERMAN, B. O Laptop de Leonardo: como o novo Renascimento já está mudando a sua vida. Rio de Janeiro: Nova Fronteira, 2006

WARSCHAUER, M. Tecnologia e inclusão social: a exclusão digital em debate. São Paulo: Editora Senac São Paulo, 2006. 